NBSIR 81-2329

\title{
Characterizing the Thermal Response of Fusible-Link Sprinklers
}

U.S. DEPARTMENT OF COMMERCE

National Bureau of Standards

National Engineering Laboratory

Center for Fire Research

Washington, DC 20234

August 1981

Final Report

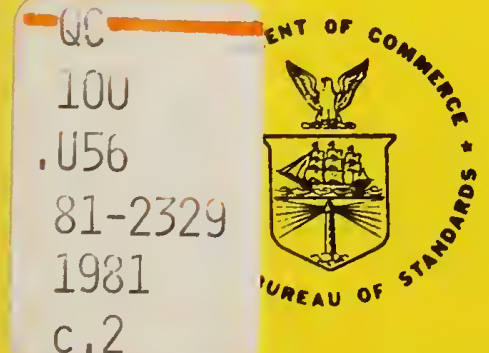

U.S. DEPARTMENT OF COMMERCE

NATIONAL BUREAU OF STANDARDS 



\section{CHARACTERIZING THE THERMAL RESPONSE OF FUSIBLE-LINK SPRINKLERS}

David D. Evans

Daniel Madrzykowski

U.S. DEPARTMENT OF COMMERCE

National Bureau of Standards

National Engineering Laboratory

Center for Fire Research

Washington, DC 20234

August 1981

Final Report

U.S. DEPARTMENT OF COMMERCE, Malcolm Baldrige, Secretary NATIONAL BUREAU OF STANDARDS, Ernest Ambler, Director 

IIST OE FIGURES . . . . . . . . . . . . . . . . IV

LIST OF TABLES .................. . . v

Abstract . . . . . . . . . . . . . . . . 1

1. INTRODUCTION ........................ 1

2. EXPERTMENTAI APPROACH . . . . . . . . . . . . 2

2.1 Apparatus for ThermaI Response Measurements . . . . 2

2.2 Sensing Eiement Instrumentation ......... 3

2.3 Measurements ................ 4

3. DISCUSSION OF MEASUREMENTS . . . . . . . . . . . 5

3. I Energy Transfer ................ 5

3.2 Models of Time Response ........... . 6

3.2.1 Single Paramerer Model . . . . . . . 6

3.2.2 Two Parameter Model ........... 8

3.2.3 Model Parameters Determined from Tests . . . 10

3.2.4 Radiation and Conduction Effects ...... 10

4. USE OF THE MODELS .................. 12

5. CONCLUSTONS ..................... 15

6. REFERENCES ........................ 15 
Figure 1. Thermal response measurement apparatus . . . . . 17

Figure 2. Instrumented sprinkler A . . . . . . . . 18

Figure 3. Instrumented sprinkler B ............ 19

Figure 4. Instrumented sprinkler C . . . . . . . . . 20

Figure 5. Sprinkler A, test link and gas temperatures . . . 21

Figure 6. Sprinkler B, test link and gas temperatures . . . 22

Figure 7. Sprinkler C, test link and gas temperatures . . . 23

Figure 8. Apparent heat capacity of sprinkler A link solder material ............ . . 24

Figure 9. Areas associated with energy transfer, sprinkler A . . . . . . . . . . . . 25

Figure 10. Ln $\left(\Delta \mathrm{T}_{\mathrm{g}}-\Delta \mathrm{T}_{\ell}\right)$ vs time for sprinkler A . . . . . 26

Figure 11. Ln $\left(\Delta \mathrm{T}_{\mathrm{g}}-\Delta \mathrm{T}_{\ell}\right)$ vs time for sprinkler B . . . . . . 27

Figure 12. Ln $\left(\Delta \mathrm{T}_{\mathrm{g}}-\Delta \mathrm{T}_{\ell}\right)$ vs time for sprinkler $\mathrm{C} . \ldots 28$

Figure 13. Polished brass disk . . . . . . . . . . 29

Figure 14. Ln $\left(\Delta \mathrm{T}_{\mathrm{g}}-\Delta \mathrm{T}_{\mathrm{q}}\right)$ vs time for polished brass disi . . . 30

Figure 15. Ln $\left(\Delta \mathrm{T}_{\mathrm{g}}-\Delta \mathrm{T}_{\ell}\right)$ vs time for black brass disk . . . 31

Figure 16. Brass disk mounted in sprinkier body . . . . . . 32

Figure 17. Ln $\left(\Lambda \mathrm{T}_{\mathrm{g}}-\Delta \mathrm{T}_{\ell}\right)$ vs time for polished brass disk mounted in sprinkler body ........... 33

Figure 18. Ceiling layer gas temperatures for mattress fire . 34 


\section{LIST OT TABLES}

Page

Table 1. Test Results and Model Sprinkler Time Response

Parameters . . . . . . . . . . . . . .

Table 2. Predicted Activation I'ime for Pendent Sprinklers in Mattress Fire . . . . . . . . . . . . . 



\title{
CHARACTERIZING THE THERMAI RESPONSE OF FUSIBLE-LINK SPRINKLERS
}

\author{
David D. Evans \\ Daniel Madrzykowski*
}

\begin{abstract}
Measurements of the thermal response of selected fusible-link sprinklers to sudden immersion into a hot gas flow are presented. Two methods of characterizing the response are detailed. One method explicitly accounts for phase change, the other does not. The methods are compared by using each to predict the response of a sprinkler to a selected mattress fire exposure.

Key Words: Fire extinguishment; fire models; fire protection; sprinkler heads; sprinkler systems; time constant
\end{abstract}

\section{INTRODUCTTON}

The overall effectiveness of an automatic sprinkler system in suppressing an unwanted fire is dependent on the time it takes to respond to the fire condition. Common automatic sprinkler systems are activated by hot combustion products, transported from the source fire, which heat a thermal control element to a predetermined activation temperature. This temperature is usually associated with some part of the sensing element undergoing phase transition.

In the specific case of the common solder type sprinkler link each increment. of energy transferred to the link from the fire in excess of energy losses raises the temnerature of the link and binding solder

\footnotetext{
*Presently at: Bechtel Corporation, Gaithersburg. Maryland
} 
materials until the solder begins to fuse. At this temperature most aditional energy goes into completing the phase transition for the solder and not into raising the link temperature. When enough solder material has fused the link ruptures, activating the sprinkler head.

The predominant mechanism for heat transfer to a sprinkler link or other thermal sensor is by convection of hot combustion products. Heat transferred by radiation during the initial fire growth period is of secondary importance $[1]^{1}$. To predict the temperature of the thermal sensing element and the time at which activation conditions are reached, the thermal response characteristics of the sensor must be determined. A useful method to characterize the thermal response of a sprinkler l.inkage is to measure the temperature response of the link to sudden immersion in a hot gas flow.

\section{EXPERTMENTAL APPROACH}

\subsection{Apparatus for Thermal Response Measurements}

Characterizing the response time of sprinkler links by sudden immersion in a hot gas flow is the basis for the present Factory Mutual Research Corporation (FMRC) piunge test [1]. For this study, an apparatus not as refined as the FMRC plunge test but sufficient for the needs of this exploratory work was constructed.

Shown in figure 1 , the apparatus consisted principally of $a$ commercial heat gun to supply a forced hot air flow to an aluminum tube (114 m ID) with a deflector plate arross the entrance to help diffuse and mix the hot air flow. The gas temperature was measured continuously near the tube outlet with a thermocouple suspended in the flow. For

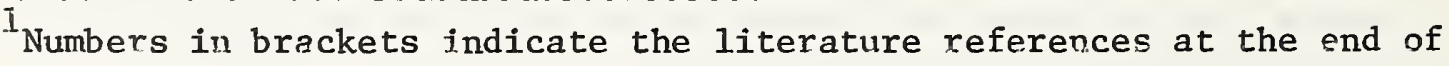
this paper.
} 
testing, sprinkler heads were placed in the supporting clamp at the exit of the tube. The clamp is arranged in such a way that the sprinkler head could be held outside the hot air flow prior to testing, but rapidly reiocated into the center of the flow to initiate testing. Generally the linkage on the head being tested was placed as close as practical to the exit of the tube without resulting in appreciable blockage to the air flow. The nominal air flow velocity across the tribe nutlet was $2.13 \mathrm{~m} / \mathrm{s}$. The turbulence level in the flow, although known to affect the heat transfer ratio, was not measured. The gas outlet temperature could be varied by controlling the voltage applied to the heating coils with an exterior variable transformer. However, a simple air flow temperature of $90^{\circ} \mathrm{C} \pm 4^{\circ} \mathrm{C}$ was used for these tests. The aluminum tube wall. was found to equilibrate at $60^{\circ} \mathrm{C} \pm 4^{\circ} \mathrm{C}$ under test conditions in the laboratory.

\subsection{Sensing Element Instrumentation}

Various methods of attaching thermocouple junctions to a fusible link in order to measure its temperature were examined. No method of. attachment of a pre-welded junction to the face of the 1ink proved mechanically rugged enough for testing. In order to instrument a link, two small holes were drilled opposite each other in the edge of the disik and fitted tightiy with one wire of an AWG-24 pair of Type $K$ thermocouple cable. The disk or link material formed the conducting path between these junctions. In an effort to minimize conduction of heat to the sensing element through the attached wires, each wire was left electrically insulated up to the junction and also mechanically formed to closely follow the edge of the link or disk. This method of instrumenting the links proved to be both mechanically rugged and repeatable without undue difficulty. 


\subsection{Measurements}

The time response characteristics of three industrial sprinklers were measured. Sprinklers A, B, and $\mathrm{C}$ are shown instrumented, each with a thermocounle connected to its thermal $1 \mathrm{ink}$, in figures 2,3 and 4. Each link had a labeled activation temperature of $74^{\circ} \mathrm{C}$. Each sprinkler was tested oriented such that the broad side of the thermal link faced the upstream direction of the hot gas flow.

Figures 5, 6 and 7 show the temperature response of the three thermal linkages in response to sudden immersion in the hot air stream, the temperature of which is also recorded in the fjgures for the duration of the test.

In each plot the temperature of the link is seen to increase in response to the heat transferred from the hot air stream up to a point when the rate of temperature rise decreases abrupt1y. This abrupt change in rate of temperature increase, which forms a plateau in the time-temperature curve, indicates the onset of phase transition in the links. Rupture of the link is indicated by the termination of the temperature plot.

Focusing on figure 5, for sprinkler A, in the plateau region the temperature is not constant, but undergoes a gradual rise from $71^{\circ} \mathrm{C}$ to $74^{\circ} \mathrm{C}$. This hehavior was shown to be reproducible in several tests. The change in link temperature during solder fusion may indicate that the sample of solder material tested was not a. true eutectic mixture, or possibly experienced non-isothermal conditions during the testing.

The fusion characteristics of the solder material used in sprinkler A were investigated with separate differential scanning calorimeter (DSC) measurements. Data from the scan is presented in figure 8 in units reflecting apparent heat capacity of the sample. For the purposes here, it is only necessary to note that melting in the solder material 
is not completed at a single temperature hut has two distinct peaks. Very little energy is associated with the second peak near $74^{\circ} \mathrm{C}$ compared with the lower temperature phase transition peaking at $67^{\circ} \mathrm{C}$. This DSC data for the solder material would suggest a. temperature response as measured for sprinkler link A (figure 5); a plateau region representing the low temperature phase transition, a silight temperature rise to the second phase transition of short duration before link rupture. It should be observed that even though the qualitative features agree, the plateau in the response curve for sprinkler A (figure 5) is at approximately $72^{\circ} \mathrm{C}$, while a range of $63^{\circ} \mathrm{C}$ to $67^{\circ} \mathrm{C}$ was suggested by the low temperature transition from the DSC measurements (figure 8 ). The reason for this discrepancy is presently unknown.

\section{DISCUSSION OF MEASUREMENTS}

\subsection{Energy Transfer}

An interesting parameter that characterizes one aspect of the sprinkler link response is the fraction of energy needed to fuse enough solder to rupture the link, compared to the total energy needed to heat the link from ambient to rupture temperature. Ignoring the effects of radiative heat transfer between the link and the surrouridings and conductive heat transfer with the sprinkler body, estimates of the above energy ratio can be calculated from the information in figures 5 , 6 , and 7 .

The convective heat transferred to the link from the hot air stream is proportional to the area between the outlet air temperature curve shown in figures 5, 6 and 7 and the respective link temperature curve. Figure 9 shows the two areas of interest for sprinkler A. The fraction of energy involved with link fusion is

$$
=\frac{\text { fusion energy }}{\text { rupture energy }}=\frac{\text { Area } A}{\text { Area }(A+B)}
$$


For sprinklers A, B and C, this fraction of the energy associated with the phase transitions in the solder, compared to the energy to rupture the link from the respective $24.2^{\circ} \mathrm{C}, 29.2^{\circ} \mathrm{C}$, and $27.4^{\circ} \mathrm{C}$, initial temperatures were: $0.26,0.31$, and 0.088 respectively. Sprinkier $C$, which had the shortest time to rupture, or nverall fastest response, also had the lowest ratio of fusion energy compared to total rupture energy.

\subsection{Models of Time Response}

The l.aboratory measurements made on the sprinkler heads established the activation time for the linkage when exposed to a particular controlled hot gas flow. To predict the activation of the same linkage under different gas velocity and temperature conditions a dynamic model for the thermal response must be formulated. Two simple models will be discussed,

\subsubsection{Single Parameter Mode1}

In the simplest moiel, the thermal response of the sprinkler linkage is characterized by a single parameter $\tau$, usually referred to as a time constant. This time constant has its basis in a simple model of the heat transfer process to the 1ink. As discussed by Heskestad and Smith [1], the equation governing the temperature-response of the sprinkler link tup to the temperature at which phase transitions begin is:

$$
\mathrm{d}\left(\Delta \mathrm{T}_{\ell}\right) / \mathrm{dt}=\tau^{-1}\left(\Delta \mathrm{T}_{\mathrm{g}}-\Delta \mathrm{T}_{\ell}\right)
$$

where $\Delta_{\ell}$ is the excess temperature of the link above the initial temperature, and $\Delta \mathrm{T}_{\mathrm{g}}$ is the excess temperature of the gas above the initial link temperature. The time constant, $\tau$, may be related to the properties of the sprinkler linkage and the gas flow for convection dominated heat trausfer according to: 


$$
\tau=\mathrm{MC} / \mathrm{h}_{\mathrm{C}} \mathrm{A}
$$

where $M$ is the mass, $C$ is the specific heat, $A$ is the area of the link exposed to gas flow, and $h_{c}$ is the convective heat-transfer coefficient. The value of $h_{c}$ and thus $\tau$ is dependent on the gas flow velocity passing over the link.

When the fusible link reaches the temperature at which phase transitions in the link solder begin, the temperature of the 1ink remains neariy constant. and is no longer predicted by equation 2 . However, an overall time constant $\tau$, that includes both the effects of thermal capacity and phase transitions in the linkage at a given gas flow velocity, is a usefuI quantity to calculate.

Equation 2 may be solved for conditions that are appropriate to model the test measurements made in this study, namely $\Delta \mathrm{T}_{\ell}=0$ at $\mathrm{t}=$ 0 and $\Delta \mathrm{T}_{\mathrm{g}}$ is a constant. For these conditions, $\Delta \mathrm{T}_{\ell}$ as a function of time found from equation 2 is

$$
\Delta \mathrm{T}_{\ell}=\Delta \mathrm{T}_{g}\left(1-\mathrm{e}^{-t / \tau}\right)
$$

By simply measuring the time to link rupture, ${ } r$, in response to sudden immersion in a hot gas flow and calculating the excess activation temperature, $\Delta \mathrm{T}_{\ell \mathrm{a}}$, the rupture temperature of the link either measured or value indicated on link minus the initial temperature of the link, an overall value for the time constant may be determined. In this study this overall time constant will be labeled $\tau_{1}$, From equation 4 its value is:

$$
\tau_{1}=-t_{r} / \ln \left(1-\Delta T_{\ell a} / \Delta T_{g}\right)
$$

If the data for the linik temperatures shown in figures 5,6 and 7 are re-plotted in the form

$$
\ln \left(\Delta \mathrm{T}_{\mathrm{g}}-\Delta \mathrm{T}_{\ell}\right)^{\prime} \text { vs. } \mathrm{t}
$$


then from equation 4 the slope of the curre will be, $-1 / \tau$. Figures 10, 11 and 12 show a re-plotting of the data from figures 5, 6 and 7 respectively as solid lines. From equation 5 the value, $-1 / \tau_{1}$ equals the slope of the straight line (shown as broken lines in figures 10, 11 and 12) connecting the first data point at time, $t=0$ and the last data point at link rupture. Thus the overall time constant $\tau_{1}$ may also be determined graphically.

This simple one parameter model for characterizing the therma1. response of the sprinkler linkage can be used effectively to predict activation times, as will be discussed later, even though fusion of the link solder is not explicitly modeled and deviations from the measured temperature response are sometimes large. The method has an advantage over the two parameter model, which will be discussed next; in that the overall time constant, $\tau_{1}$, may be determined without measuring the link temperature history. Only the initial link temperature (room temperature), time to link rupture in hot gas flow, and rupture tempexature (link activation temperature) are needed to determine, $\tau_{1}$.

\subsubsection{Two Parameter Model}

The single parameter model described in the previous section is the simplest characterization of the thermal response of the sprinkler linkage. As can be easily seen from figures 10, 11 and 12, there is a large deviation of the modeled link temperature compared to the measured values. A better correspondence between measured and predicted link temperature may be obtained from a two parameter model. For the two parameter model, a time constant, $\tau_{2}$, is used to characterize the response of the link up to the time of phase transition. Another constant is introduced to characterize the time delay from the onset of phase transition to link rupture.

To determine the two parameters for the model, two times must be measured. As with the one parameter model., the time to link rupture, ${ }^{\tau} r$, is needed. In addition, from plots of the experimental data such 
as the solid lines in figures 10, 11 and 12 , the time of an abrupt. change in slope, $t_{p}$, signifying the onset of phase transition is needed. As with the single parameter model, a time constant, $\tau_{2}$, can be calculated using equation 5 with $t_{r}$ replaced by $t_{p}$. Thus

$$
\tau_{2}=-t_{p} / 1 n\left(1-\Delta T_{2 a} / \Delta T_{g}\right)
$$

The slope of the straight broken line from the initial data point continuing to time $t_{p}$ as shown in figures 10,11 and 12 , for the sprinklers tested, is equal to $-1 / \tau_{2}$. The temperature at which this line terminates, at time $t_{p}$, corresponds to activation temperature of the link.

The time delay from the onset of phase transition to link rupture, $t_{r}-t_{p}$ is determined from the experimental data. The temperature of the link during this time interval is modeled as constant at the activation temperature. This corresponds to the horizontal broken line in figures $10,1.1$ and 1.2 .

This time delay itself is not a useful parameter for modeling the sprinkler response, because it will vary with the rate of heat transfer to the Iinkage. Applying the convective heat transfer analysis, a total energy transfer to the link during the time interval $t_{p}$ to $t_{r}$ can be determined. This change in link energy associated with melting enough solder in the link to cause rupture, is likely to be insensitive to heat transfer rate. In the two parameter model this change in link energy, $\Delta E$, will be considered a parameter for the link.

Incorporating the simplification of the two parameter model, the temperature of the Iink is constant over the time period from the onset of phase transition to link rupture. Therefore the convective energy transfer to the link ouring this time interval is:

$$
\Delta E=h A\left(\Delta T_{g}-\Delta T_{\ell a}\right)\left(t_{r}-t_{p}\right)
$$


The quantity hA is determined from $\tau_{2}$, thus equation 8 becomes:

$$
\Delta \mathrm{E}=\mathrm{MC}\left[\frac{1}{\tau_{2}}\left(\Delta \mathrm{T}_{\mathrm{g}}-\Delta \mathrm{T}_{\ell \mathrm{a}}\right)\left(\mathrm{t}_{\mathrm{r}}-\mathrm{t}_{\mathrm{p}}\right)\right]
$$

The quantity $\triangle \mathrm{E} / \mathrm{MC}$ can be determined from the experimental data and is a parameter for the linkage.

\subsubsection{Mode1 Parameters Determined from Tests}

In additjon to the values of the parameters characterizing the response curves being indicated on figures 9 through 14, tabulated values of experimental measurements and calculated parameters for the three sprinkiers are given in tabie 1 .

\section{Table 1}

Test Results and Mode1 Sprinkler Time Response Parameters

\begin{tabular}{|c|c|c|c|c|c|c|c|c|}
\hline & $\mathrm{T}_{0}$, & $\mathrm{T}_{\mathrm{g}}$, & $\mathrm{T}_{\ell \mathrm{a}}$; & $t_{p}$ & $t_{r}$, & $\tau_{1}$ & $\tau^{\tau}$ & $\Delta \mathrm{E} / \mathrm{MC}$ \\
\hline Sprinkler & ${ }^{\circ} \mathrm{C}$ & ${ }^{\circ} \mathrm{C}$ & ${ }^{\circ} \mathrm{C}$ & $\mathrm{sec}$ & sec & $\mathrm{sec}$ & $\mathrm{sec}$ & ${ }^{\circ} \mathrm{C}$ \\
\hline A & 24.2 & 87.9 & 73.2 & 118 & 194 & 132 & 80.5 & 13.9 \\
\hline B & 29.2 & 93.7 & 76.7 & 103 & 182 & 136 & 77.2 & 17.4 \\
\hline C & 27.4 & 89.0 & 72.3 & 89 & .106 & 81.2 & 68.2 & 4.16 \\
\hline
\end{tabular}

\subsubsection{Radiation and Conduction Effects}

The analysis of data for thermal response of the sprinkler links developed in sections 3.2 .1 and 3.2 .2 assumes that the heat transfer to the Iinks is dominated by convection. Radiation and conduction heat transfer to the Iink are not considered in the analysis. The time response characteristics of a machined brass disk similar in size and geometry to common fusibie links was studied under the same test conditions as used for the sprinkler measurements. These measurements form a basis for qualitative discussion of radiacion and conduction effects in the test apparatus. 
Figure 13 shows the polished brass disk suspended within a ring by cotton threads. In this configuration radiation heat transfer between the disk and the surroundings have been minimized by polishing the disk. Conduction heat transfer between the disk and the metal support is minimized by suspension of the disk with long cotton threads. Heat transfer to the disk in this configuration should be dominated by convection. Heat transfer to the disk from a constant temperature and constant velocity air flow is characterized by a constant convective heat transfer coefficient, $h_{c}$. From equation 4 , the value of the time constant, $\tau$, will consequently be constant, and the slope of the thermal response data on a plot of $\ln \left(\Delta \mathrm{T}_{\mathrm{g}}-\Delta \mathrm{T}_{\mathbb{R}}\right)$ vs. time from equation 5 will be a straight line.

Figure 14 shows the test data. for the polished brass disk suspended in the ring holder. This data falls along a straight line, indicating that as initialiy assumed, in this apparatus convection alone is the dominate mode of heat transfer to this disk. The slope of the straight line indicates that the disk has a time constant of 97 seconds. Also indicated on the graph is the point at which the disk temperature reached $74^{\circ} \mathrm{C}$. Normally this wouid be the termination point of common fusible linik tested.

Blackening the surfaces of the disk with a coating of carbon black, and retesting it in the apparatus provide a set of response data in which radiative heat transfer between the disk and its surroundings is favorable. Figure 1.5 shows that under these conditions, the response data no longer forms a straight line as in figure 14. As the disk increases in temperature, the aata bends away from the initial straight line which had a slope equivalent to a time constant of 97 seconds. The change in slope of the data indicates a gradual increase in the time constant for the disk. This apparent increase in time constant is the result of heat loss from the disk to its surroundings by radiation. 
From the data in figure 15, which represents favorable conditions for radiative heat loss in the apparatus, an estimate of the expected influence of radiation in the test data for sprinklers $A, B$ and $C$ may be obtained.

The blackenea disk reached $74^{\circ} \mathrm{C}$ in 159 seconds. Using equation 5 , with an initial temperature of $20.3^{\circ} \mathrm{C}$ and gas temperature of $91.8^{\circ} \mathrm{C}$, the time constant for the aisk would be calculated as 114 seconds. This differs by only 18 percent from the value of 97 seconds hased on the initial siope of the curve. The influence of radiative transfer could be further minimized by increasing the temperature of the gas flow and thereby increasing the dominance of the convective component. of heat transfer.

When the sprinkler link is instalied in the body of the sprinkler heat transfer between the body and the link by conduction can influence the time constant of the link. For completeness, the polished brass disk, already shown to minimize raảiative heat transfer, was mounted in piace of the tusible link in a modified link and lever sprinkler body as shown in figure 16 .

This installation was tested. The response data is presented in figure 1.7. The initial slope of the curve indicates that the installation of the brass disk in the sprinkler body has increased its time constant to 119 seconds from the previous value of 97 seconds. The increase in time constants indicates the djsk is losing heat by conduction to the sprinkler body, which because of its larger mass does not heat as fast as the link in the hot air flow.

\section{USE OF THE MODELS}

Each of the two models presented to characterize the response time of sprinklers can be used to predict the activation time for sprinklers given the air temperature and velncity history of the fire gases passing 
the sprinkier head. This type of prediction has been done previously by Alpert [2] using the one parameter model. Of particular interest in this study is the comparison of the differences between the predicted activation times in response to given fire conditions for the one and two parameter models. Using data for the air temperature just below the center ceiling from a test in which a polyurethane mattress was burned in a $3.35 \mathrm{~m} \times 4.22 \mathrm{~m} \times 2.35 \mathrm{~m}$ height room, predictions of the activation time based on the two models of sprinkler response may be made,

Although jt is known that both the temperature and velocity of the air flow past a sprinkler infiuence its response time (Alpert [2]), for the purpose of comparing the two response models velocity variation will be neglected. For simplicity the velncity of the air flow will be assumedi constant and equal to the value used in the test apparatus, $2.13 \mathrm{~m} / \mathrm{s}$.

Figure 18 shows a plot of ceiling layer gas temperature vs. time for the initial growth period of a typical mattress fire [3]. From this given gas temperature history, the activation time of each of the three sprinklers tested, A, B and C using both the one and two parameter models may be predicted. Using the one parameter model calculation of the activation time is straight. forward. Equation 2 may be integrated numerically for $\Delta \mathrm{T}_{\ell}$ as a function of time following a Runga-Kutta. procedure [4] using values of $\Delta \mathrm{T}_{\mathrm{g}}$ determined from figure 18 at five second intervals, and measured time constant $\tau_{1}$ for the sprinkler of interest. The time at which the predicted link temperatures reach the value of activation temperature measured in the laboratory test, (approximately $74^{\circ} \mathrm{C}$ for the sprinkler examined in this study) is the predicted activation time.

Using the two parameter model, link temperatures up to the activation temperature are predicted as above with time constant $\tau_{2}$ replacing $T_{1}$. In this case activation is delayed by the time necessary 
to transfer heat used in fusing the material, $\triangle \mathrm{E} / \mathrm{MC}$ from equation 7. Activation occurs when the critical value of $\triangle \mathrm{E} / \mathrm{MIC}$ is reached, which for the case of non-constant gas temperature is slightiy more compilicated than equation 9 and requires an integration over time of:

$$
\Delta E / M C=\frac{1}{\tau_{2}} \quad \int_{t_{p}}^{t r}\left(\Delta T_{g}-\Delta T_{l a}\right) d t
$$

Table 2 presents the results of calculations for predicted activation of each of the three sprinklers evaluated using the two modeis. Predicted activation times using the single parameter model. span a range of 34.3 seconds, from 2.16 .6 for sprinkler $C$ to 250.9 for sprinkler $B$. This reflects the faster response of an 81.2 second time constant, $\left(\tau_{1}\right)$, sprinkler compared to a 136 second sprinkler. In a11 cases the two parameter model predicts a shorter activation time. The difference is a slight 1.6 seconds for sprinkler $\mathrm{C}$, and a greater 8.2 seconds and 8.7 seconds for sprinklers $A$ and $B$ respectively.

Table 2

Predicted Activation Time for Pendent Sprinklers in Mattress Fire Activation Time

(Seconds)

Sprinkler

One parameter mode1

'Two parameter model
A

243.2

235.0

250,9

216.6

2.42 .2

215.0

As would be expected, when the effects of phase transitions represent oniy a smail part of the response characteristic (figure 12) of the sprinkler as in the case of sprinkler $C$, the one and two parameter models predict almost identical. activation times, 216.6 seconds and 215.0 seconds respectively. For sprinklers $A$ and $B$, the effects of phase transition are more pronounced (figures 10 and 11 ) and differences 
in predicted activation times of slightly more than 8 seconds occur in response to the selected mattress fire (figure 18). Overall, the differences in predicted activation times noted above are within the expected accuracy of either model, as well as the degree of repeatability of thermal response between different specimens of the same model sprinkler.

\section{CONCLUSIONS}

Measurements performed have shown that for selected fusible link sprinklers, the amount of energy associated with fusion of the link can be as much as 31 percent of the total energy transfer needed to rupture a link which was initially at room temperature.

Using measurement of the link temperature response to sudden immersion in a hot gas flow, two simple models can be formulated to represent the thermal behavior. When used to predict sprinkler activation time in selected fire conditions, the models produce slightly different results. The difference is, however, within the expected accuracy of the predicted method and repeatability of the sprinkler hardware.

Radiation effects in the present laboratory measurement could increase measured time constants by as much as 18 percent under worst case conditions. Conduction through link arms in one sprinkler design increase the measured individual link time constant by 23 percent.

\section{REFERENCES}

[1] Heskestad, G. and Smith, H., Investigation of a New Sprinkler Sensitivity Approval Test: The Plunge Test. Factory Mutual Technical Report, Nn. 22485, December 1976. 
[2] Alpert, R. L., Calculation of Response Time of Ceiling-Mounted Fire Detectors, Fire Technology, August 1972, p. 181-195.

[3] Hayes, D. H., Jr. and Zile, R. H., Study of the Effect of Location on the Activation Time of an Automatic Sprinkler, NBSIR in process.

[4] Young, D. M. and Gregory, R. T., A Survey of Numerical Mathematics Vo1. 1, Addison-Wesley Publishing Company, 1972. 


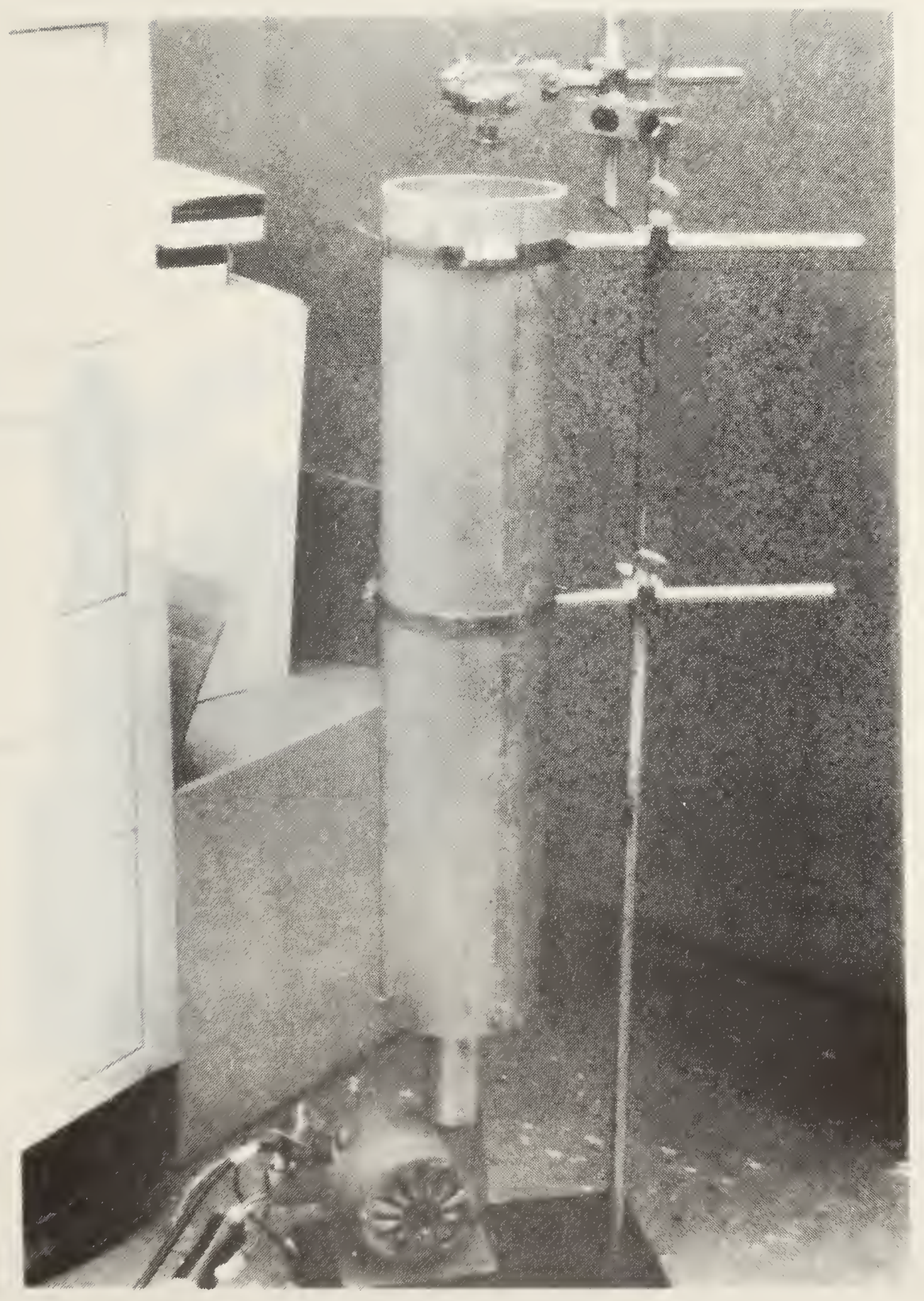

Figure 1. Thermal response measurement apparatus 


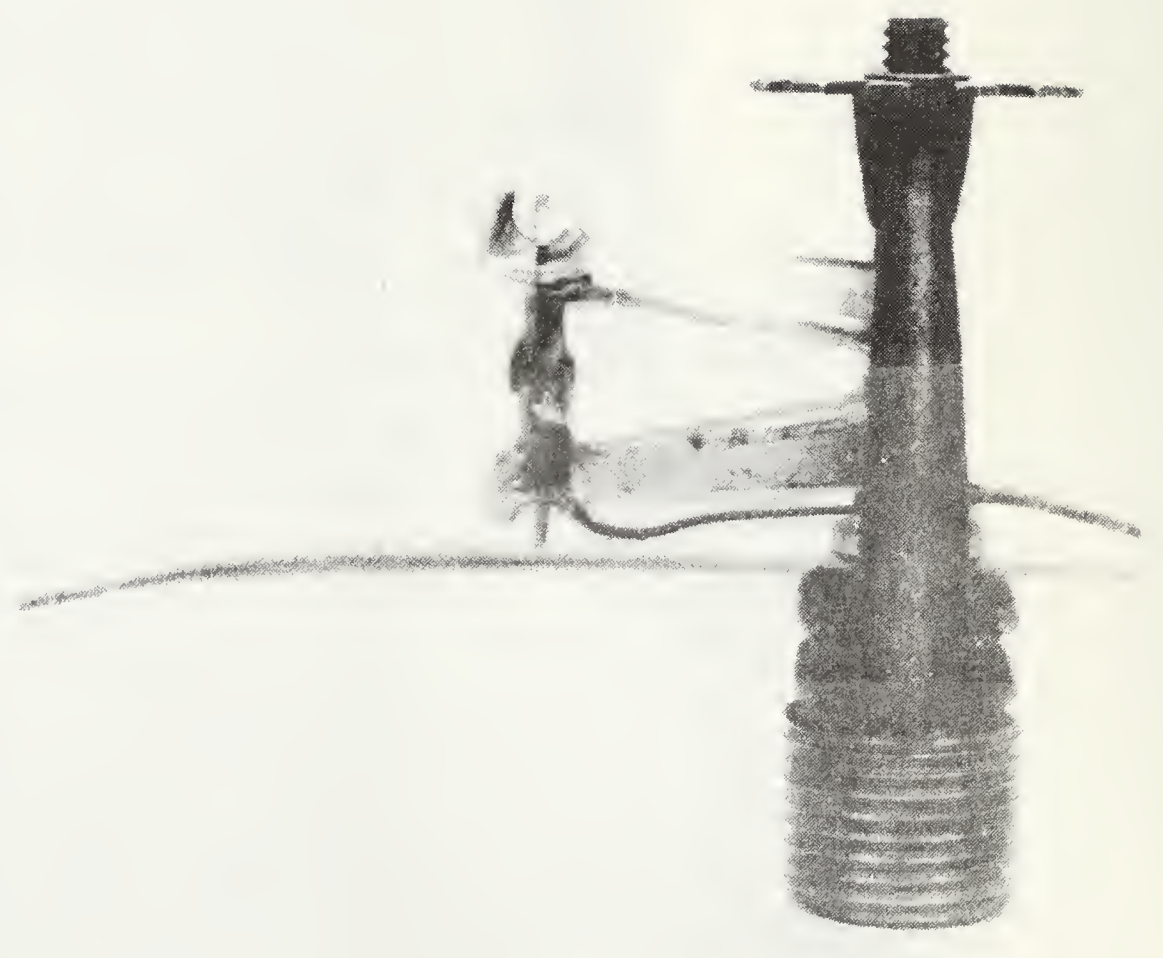

Figure 2. Instrumented sprinkler A 


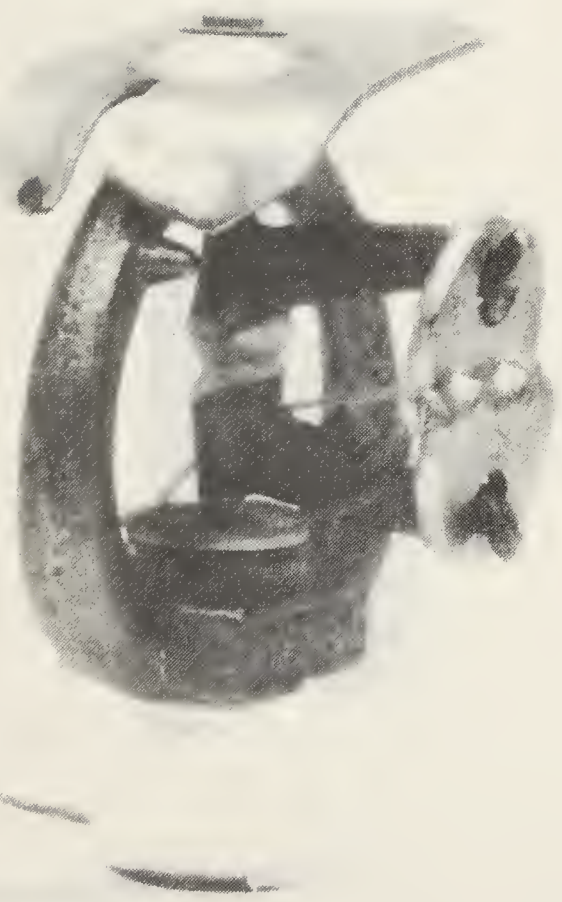

Figure 3. Instrumented sprinkler B 


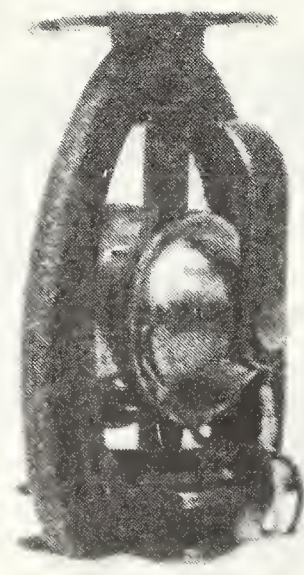

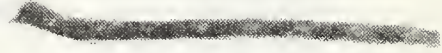

Figure 4. Instrumented sprinkler C 


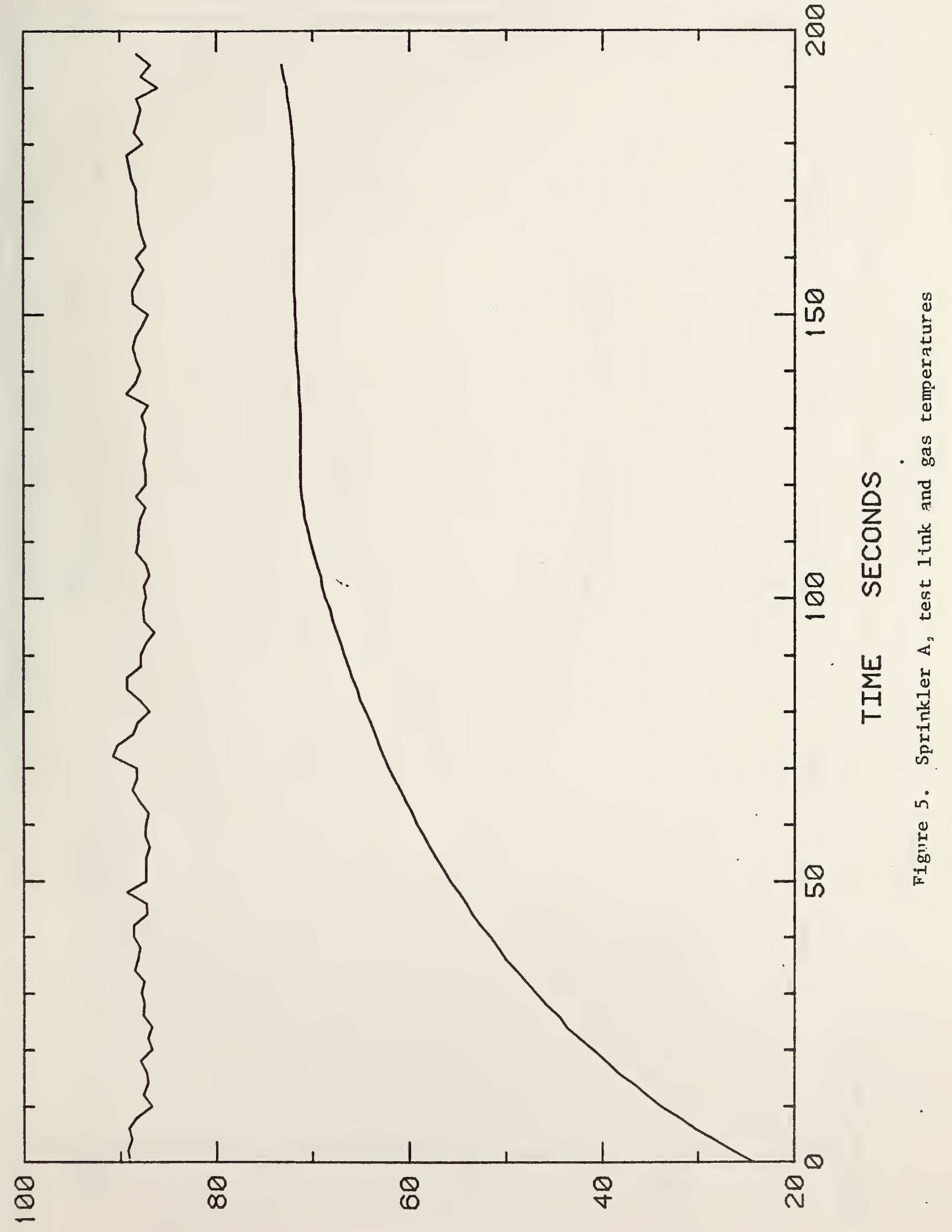

ว $\exists \forall \cap \perp \forall y \exists d W \exists \perp$ 


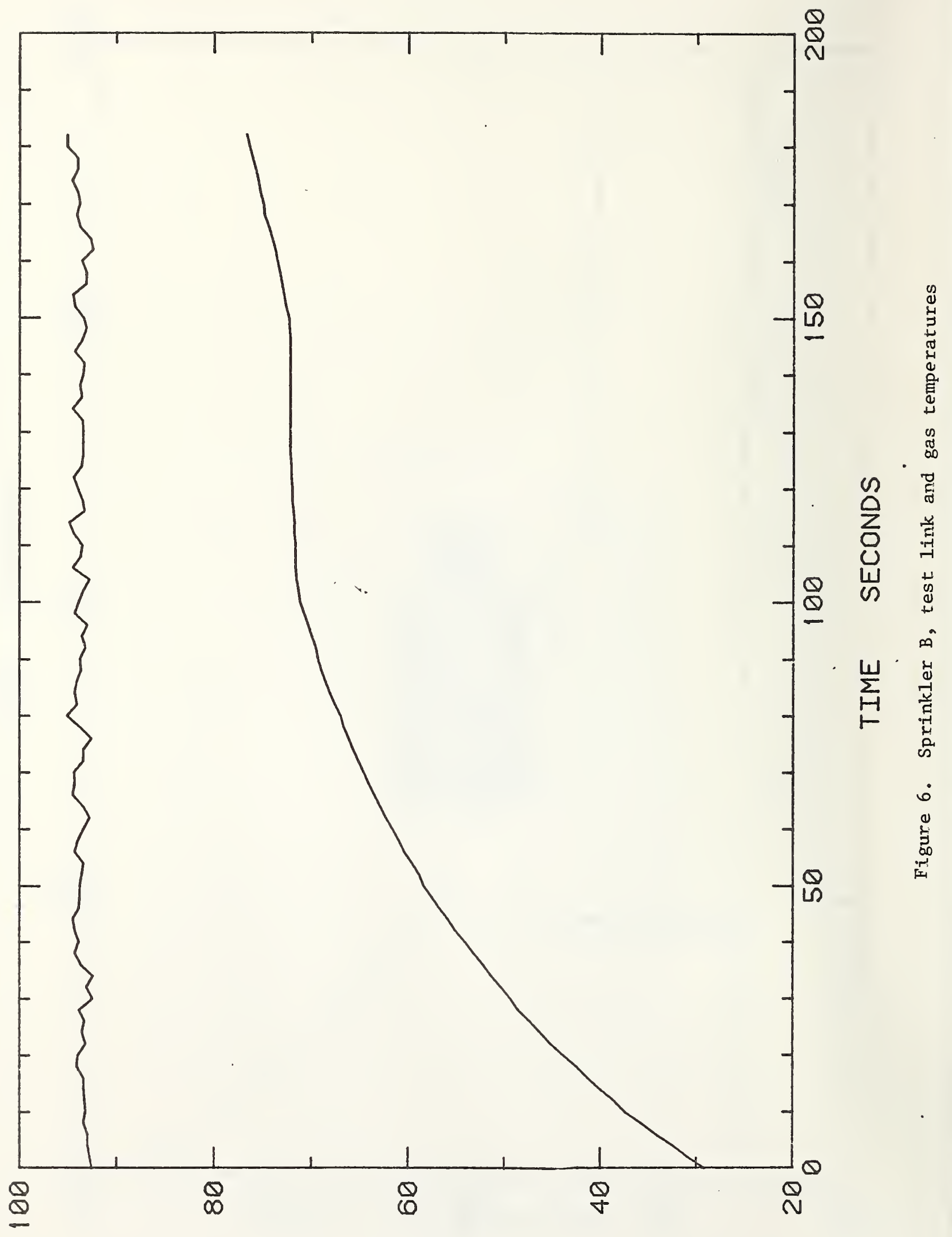

$2 \quad \exists \searrow \cap \perp \forall \forall \exists d W \exists \perp$ 


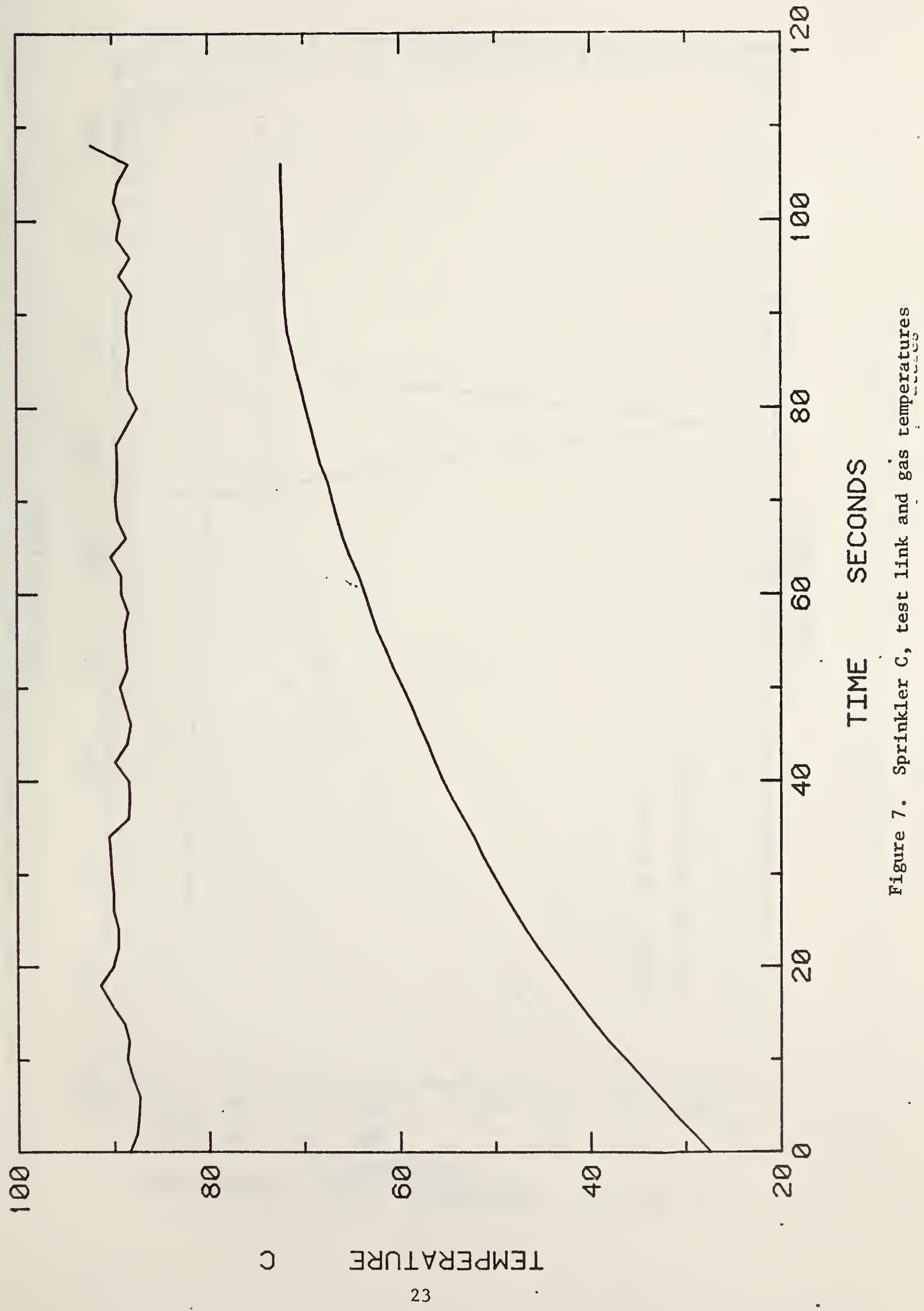




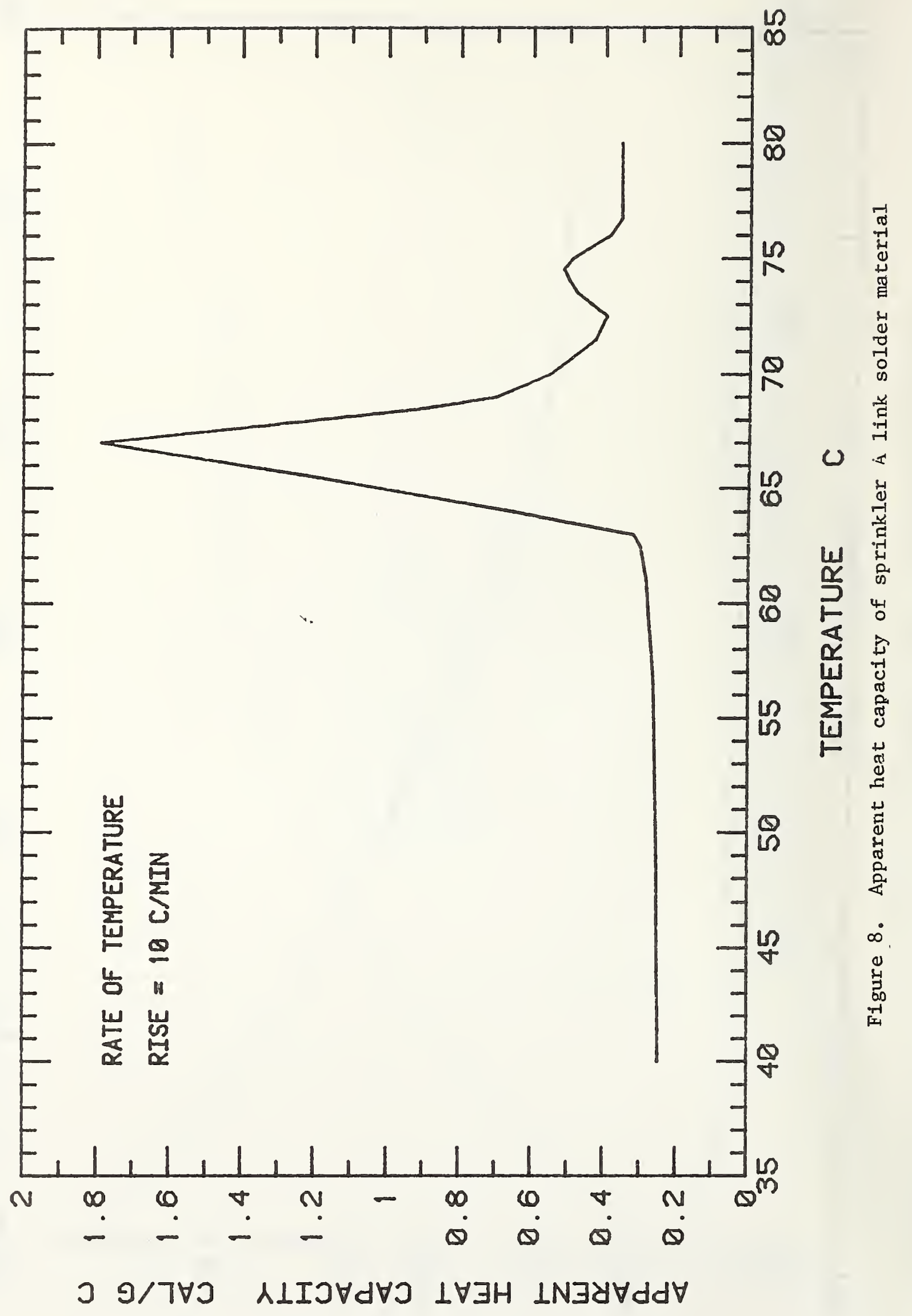




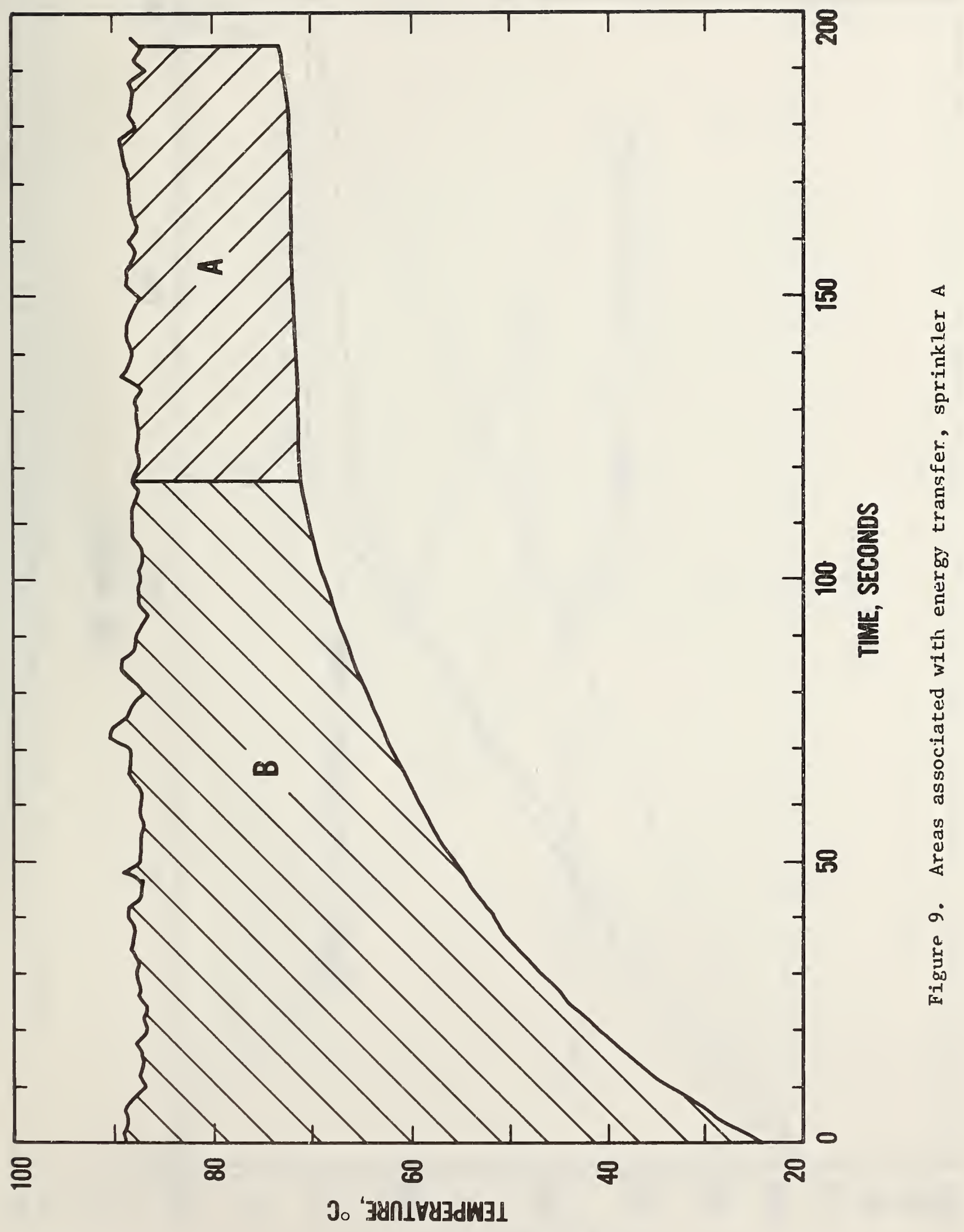




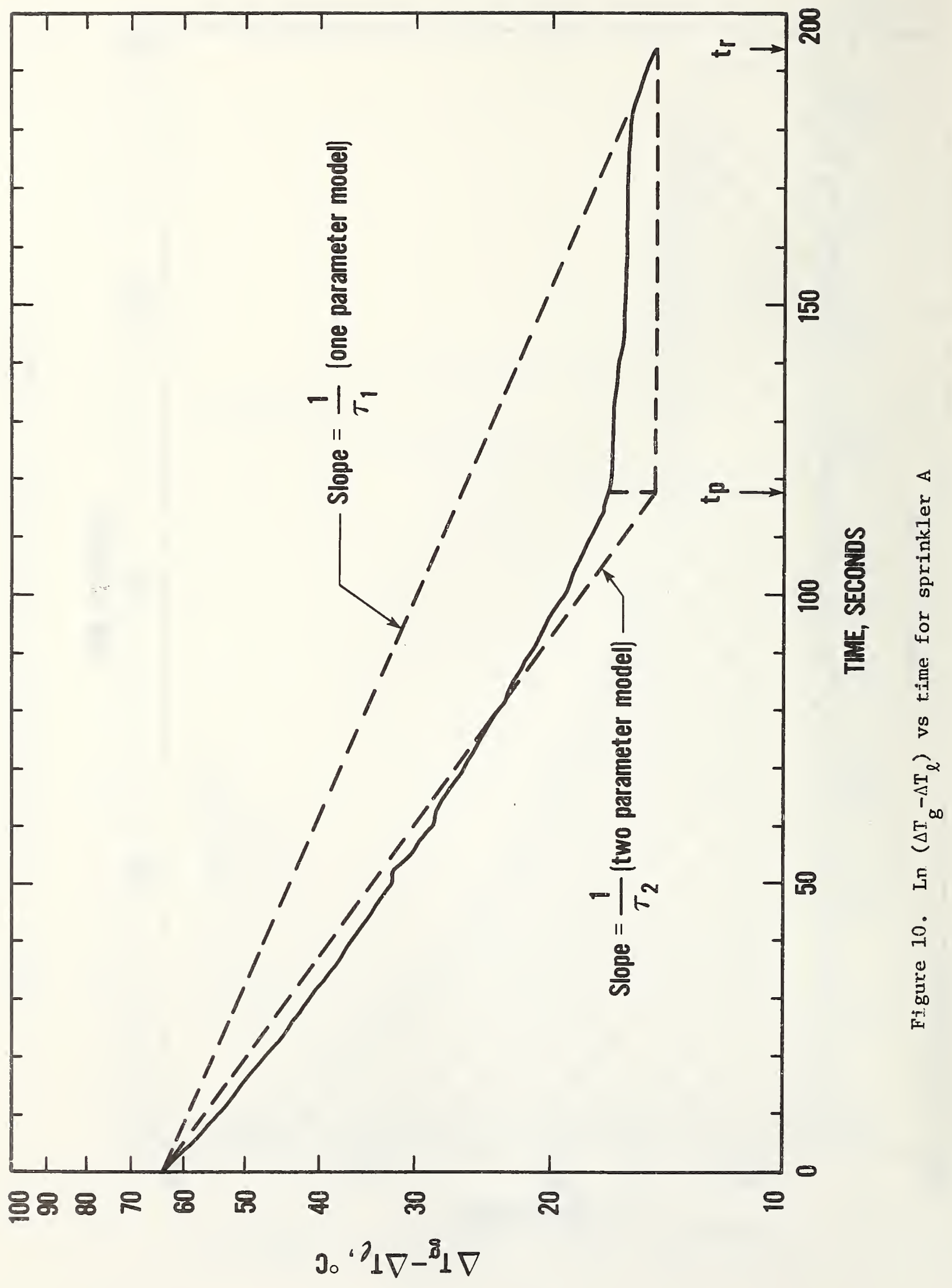




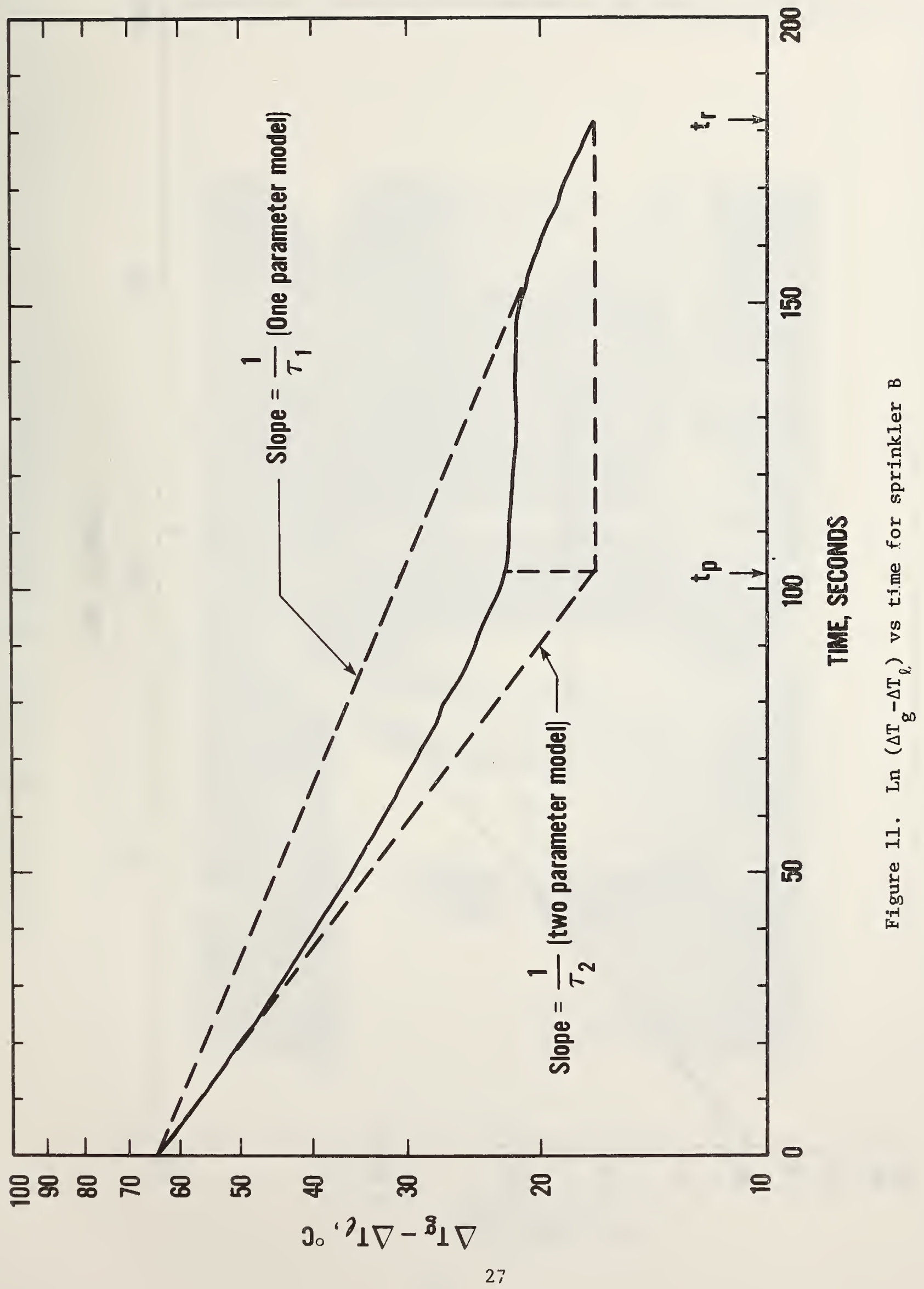




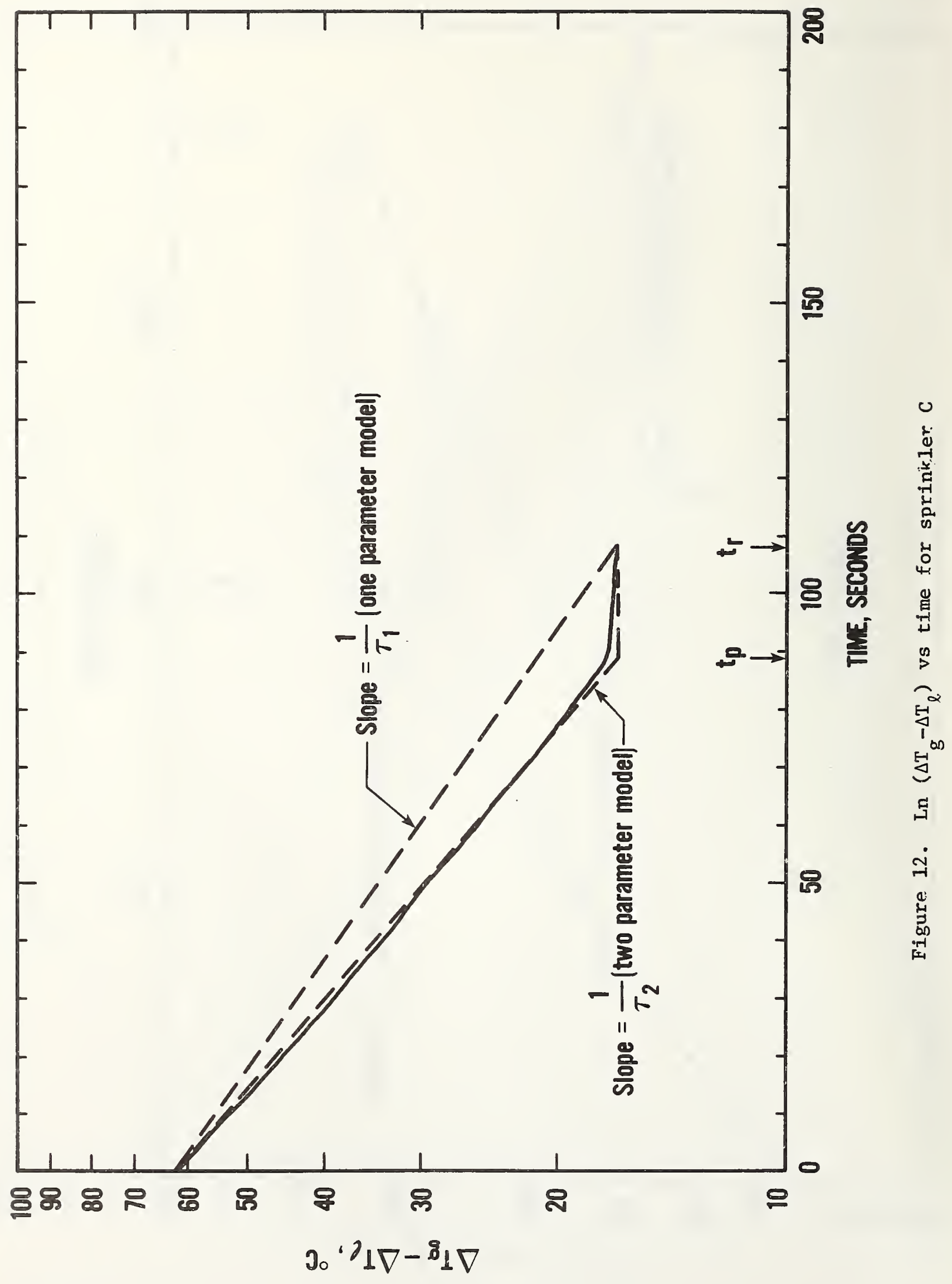




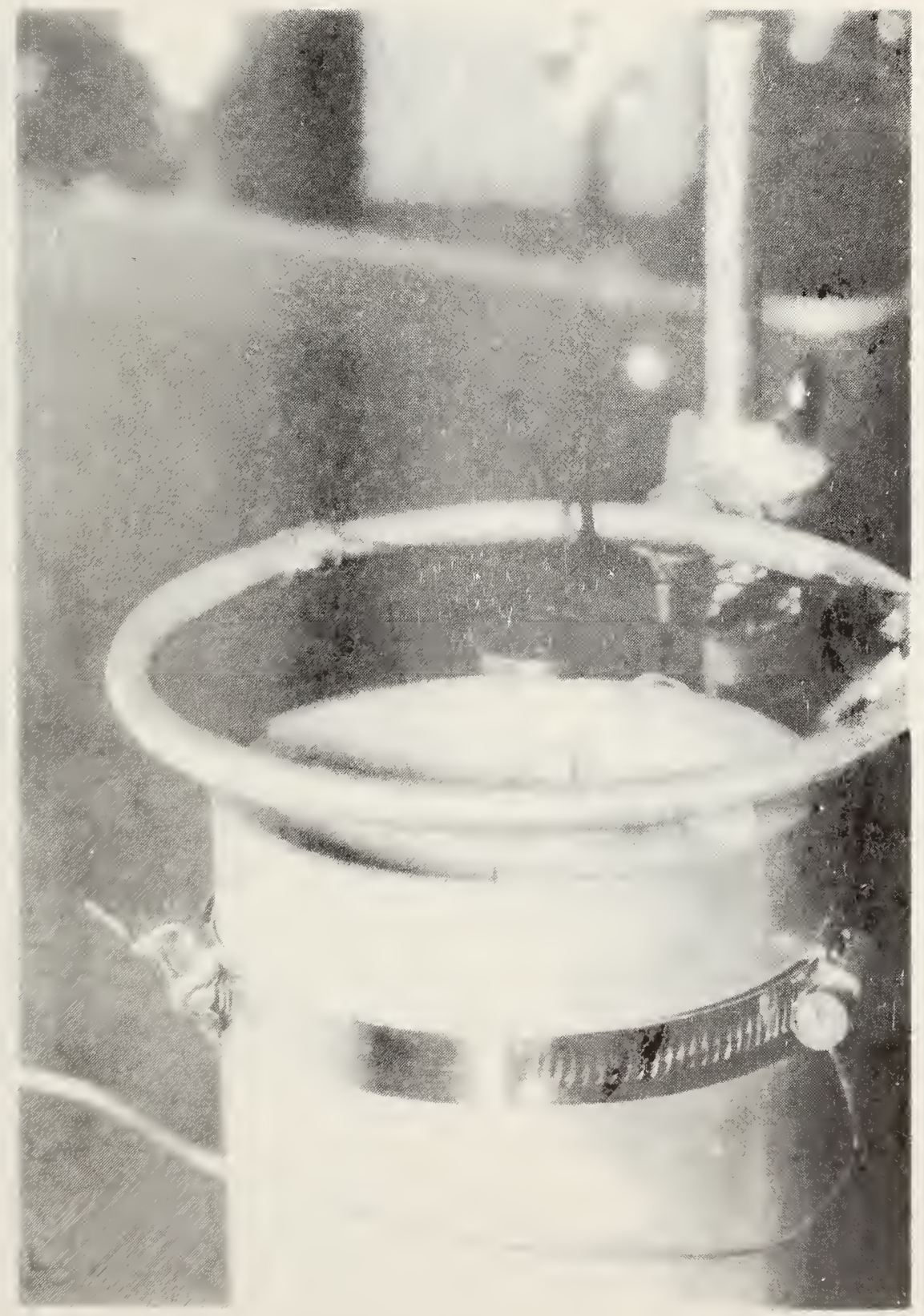

Figure 13. Polished brass disk 


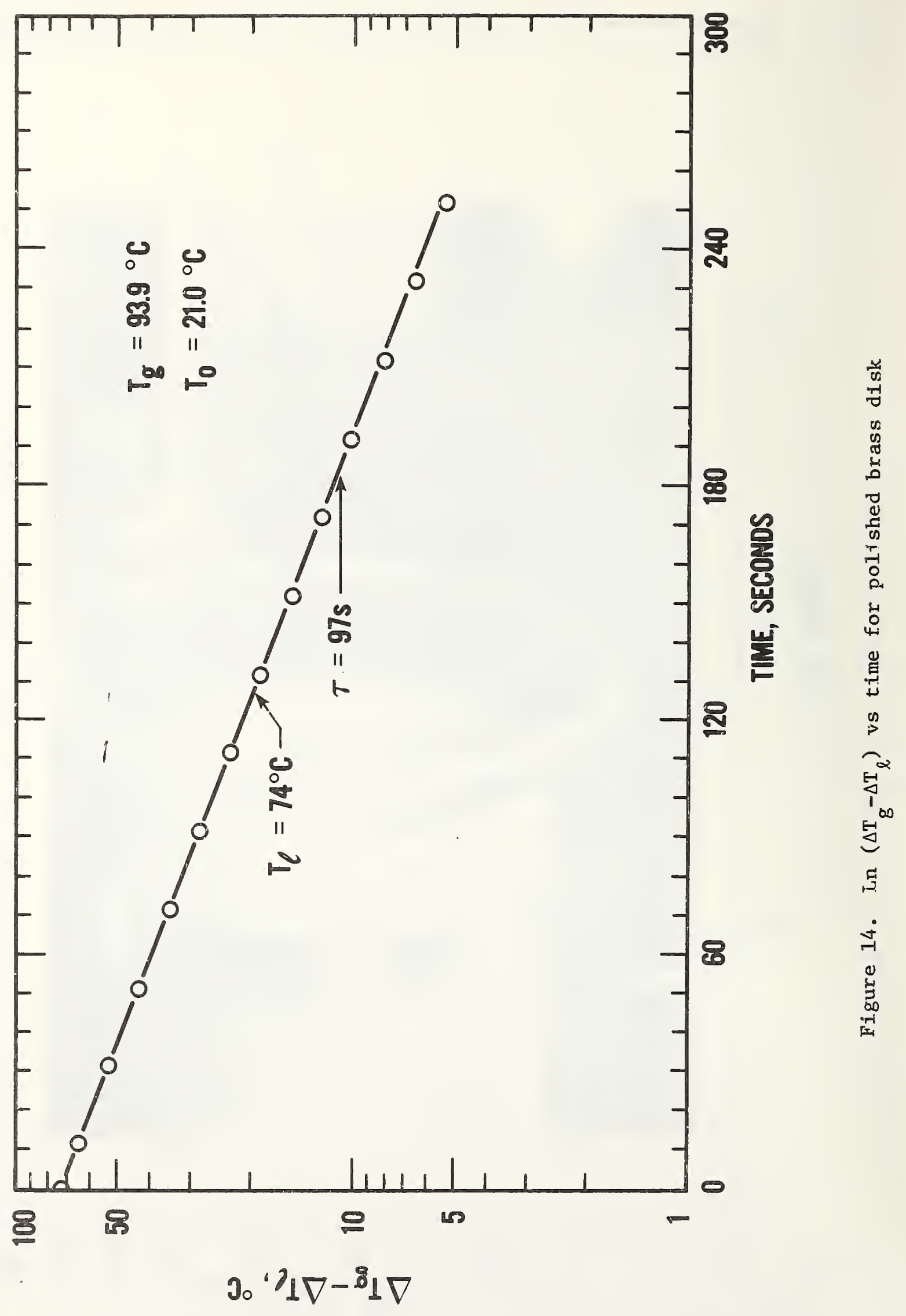




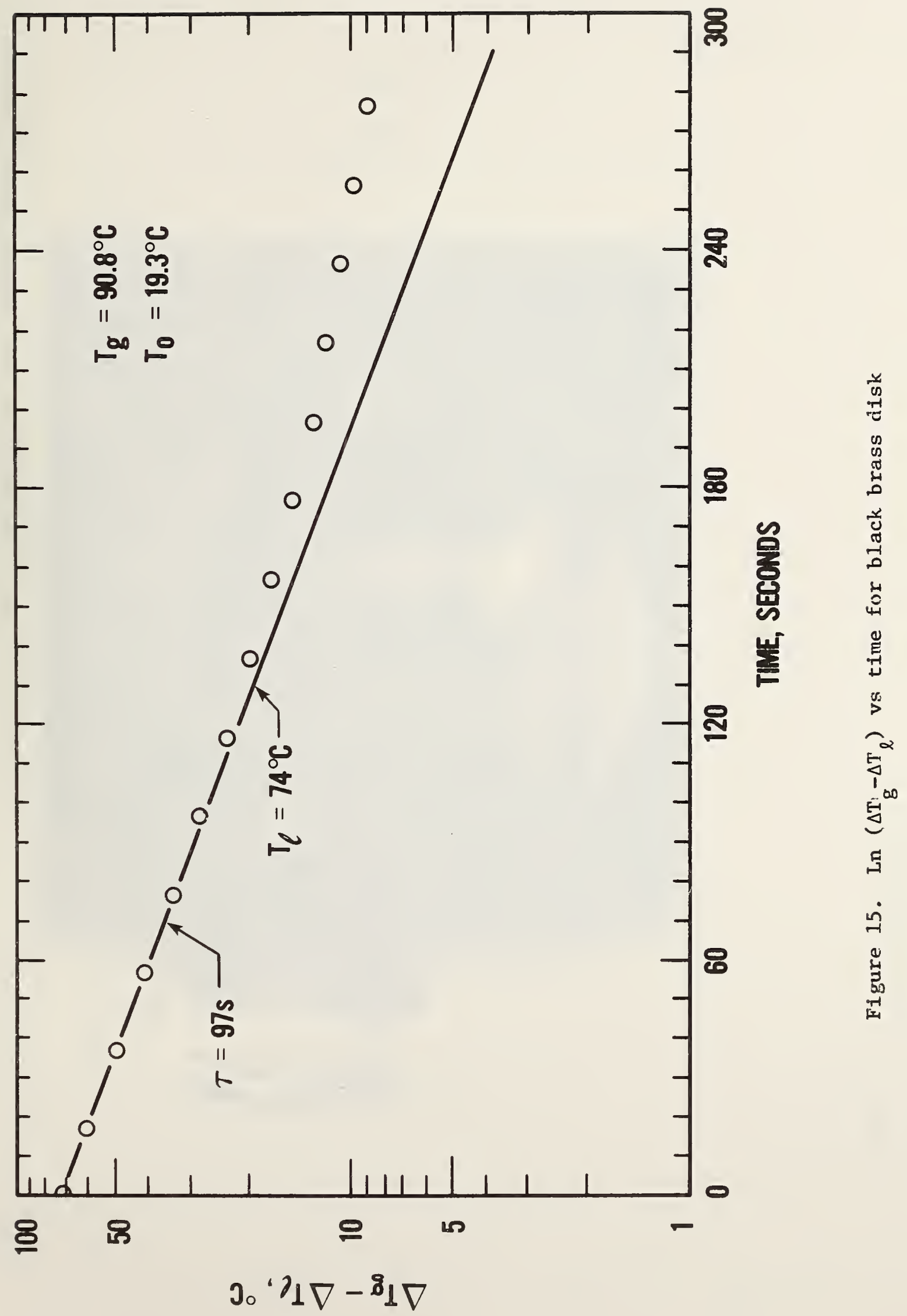




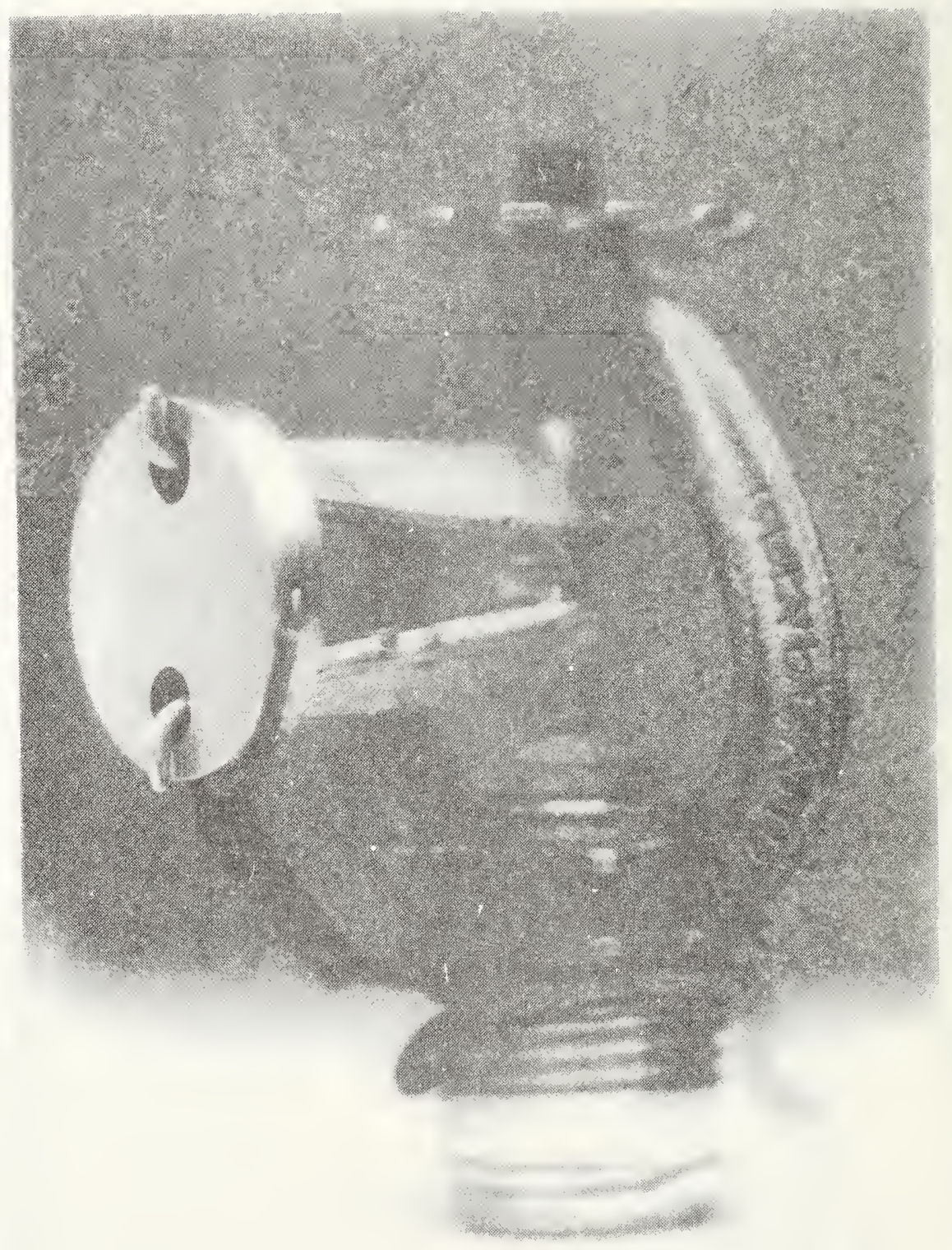

Figure 16. Brass disk mounted in sprinkler body 


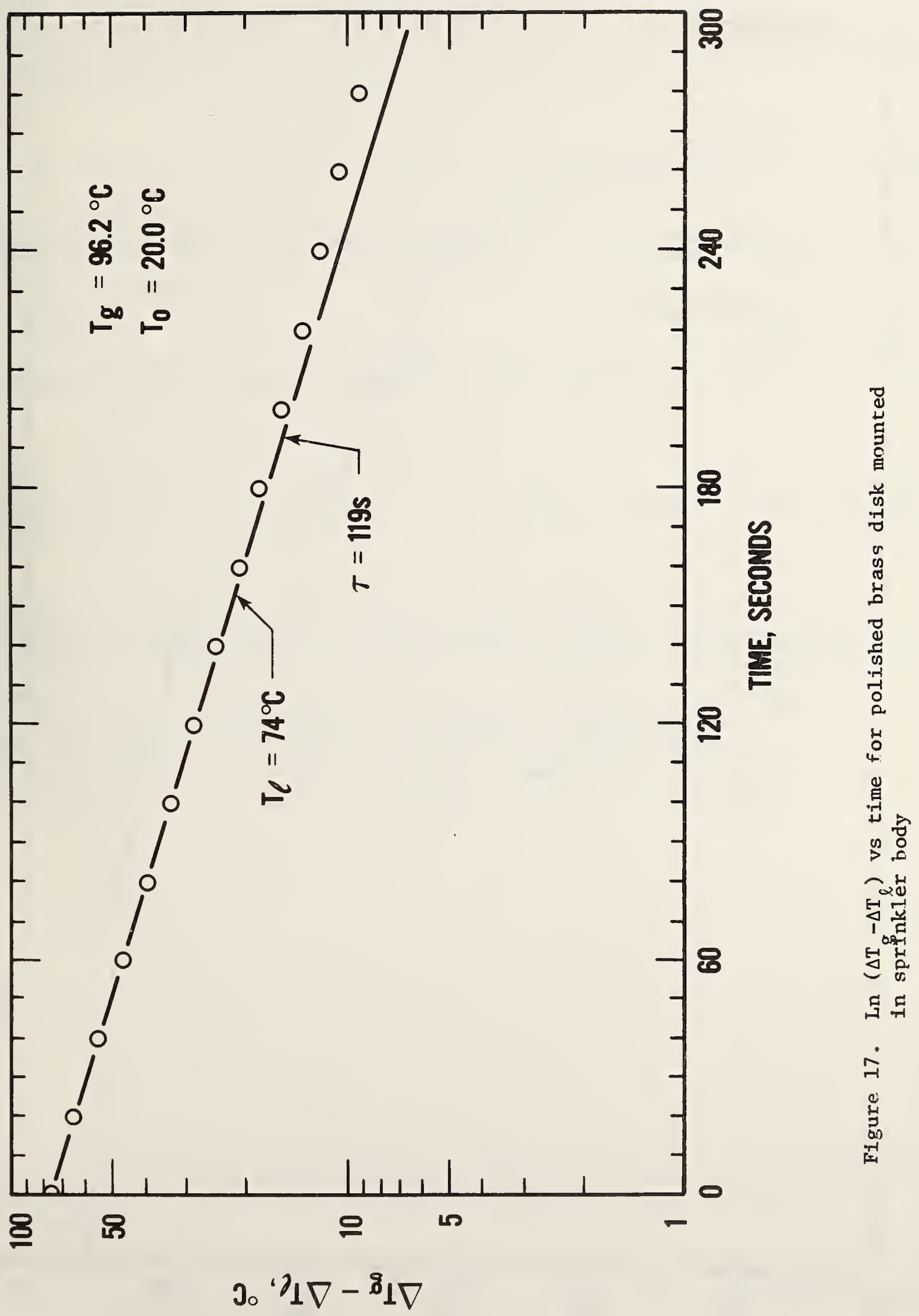




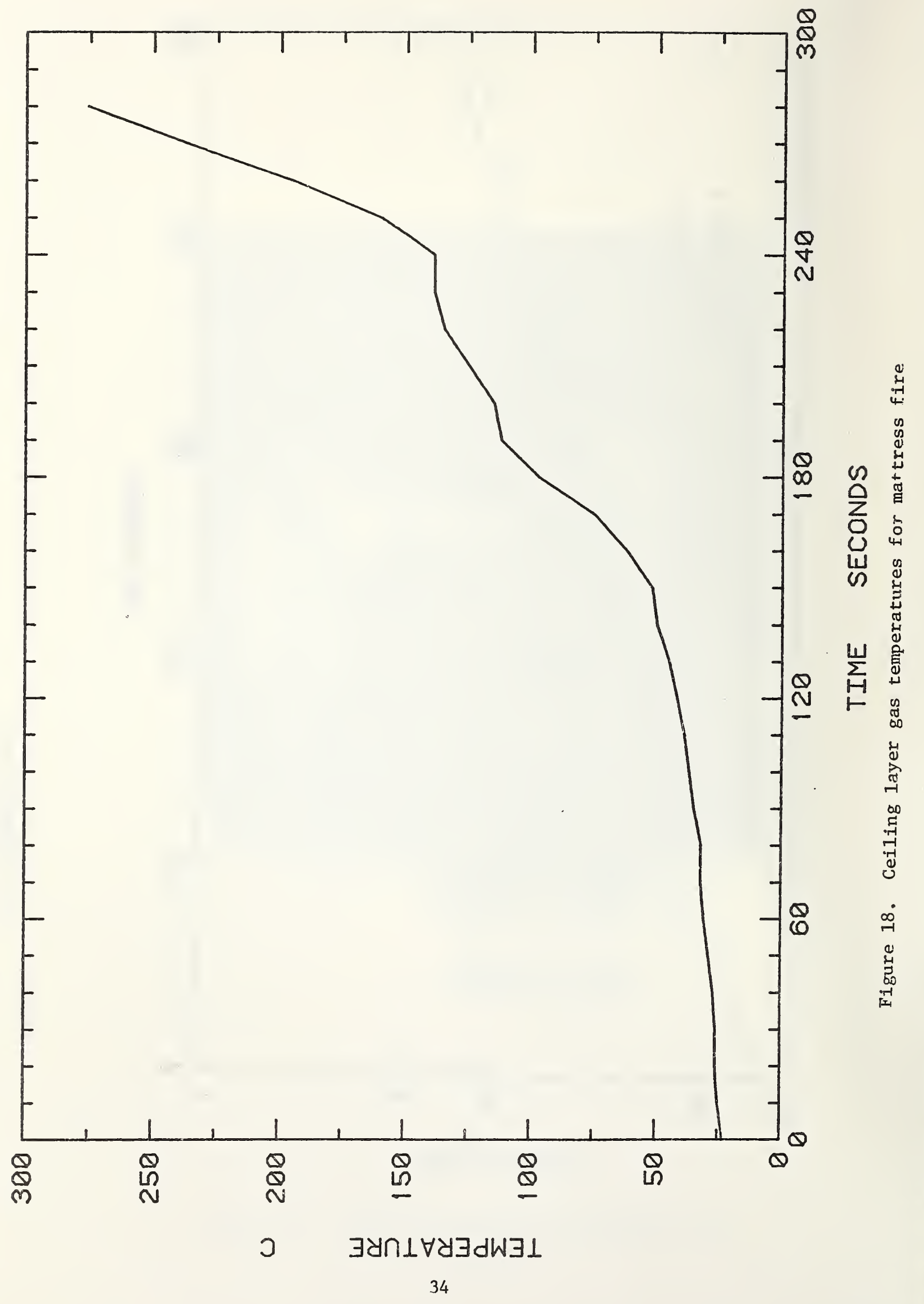


4. TITLE AND SUBTITLE

CHARACTERIZING THE THERMAL RESPONSE OF FUSIBLE-LINK SPRINKLERS

\section{5. $A \cup T H O R(S)$}

David D. Evans and Daniel Madrzykowski

6. PERFORMING ORGANIZATION (If joint or other than NBS, see in structions)

7. Contract Grant No.

MATIONAL BUREAU OF STANDARDS

DEPARTMENT OF COMMERCE

WASHINGTON, D.C. 20234

8. Type of Report \& Period Covered

Final Report

9. SPONSORING ORGANIZATION NAME AND COMPLETE ADDRESS (Street, City, Stote , ZIP)

10. SUPPLEMENTARY NOTES

D Document describes a computer program; SF-185, FIPS Software Summary, is attached.

11. ABSTRACT (A 200-word or less factual summary of most significant information. If document includes a significant bibliography or literoture survey, mention it here)

Measurements of the thermal response of selected fusible-link sprinklers to sudden immersion into a hot gas flow are presented. Two methods of characterizing the response are detailed. One method explicitly accounts for phase change, the other does not. The methods are compared by using each to predict the response of $a$ sprinkler to a selected mattress fire exposure.

12. KEY WORDS (Six to twelve entries; alphabetical order; capitalize only proper names; and separate key words by semicolons) Fire extinguishment; fire models; fire protection; sprinkler heads; sprinkler systems; time constant

\section{AVAILABILITY}

XXunlimited

$\square$ For Official Distribution. Do Not Release to NTIS

$\square$ Order From Superintendent of Documents, U.S. Government Printing Office, Washington, D.C. 20402.

$[x]$ Order From National Technical Information Service (NTIS), Springfield, VA. 2216I
14. NO. OF PRINTED PAGES

\section{9}

15. Price

$\$ 6.50$ 

